\title{
Evidence of an Increased Prevalence of Multiple Sclerosis: A Population-Based Study of Tehran Registry during 1999-2018
}

Amir Almasi-Hashiani

Arak University of Medical Sciences

Mohammad Ali Sahraian

Tehran University of Medical Sciences

Sharareh Eskandarieh ( $\sim$ sh_eskandarieh@yahoo.com )

Tehran University of Medical Sciences

\section{Research article}

Keywords: Epidemiology, Iran, Multiple Sclerosis, Prevalence, Tehran

Posted Date: April 9th, 2020

DOI: https://doi.org/10.21203/rs.2.21220/v2

License: (c) (i) This work is licensed under a Creative Commons Attribution 4.0 International License. Read Full License 


\section{Abstract}

Background: The epidemiological characteristics of multiple sclerosis (MS) have been investigated in various studies, which have revealed that the prevalence of MS varies across countries. The present study was conducted to investigate the longitudinal prevalence of MS in Tehran, Iran.

Methods: The present population-based study was conducted in Tehran, the capital of Iran from 1999 to 2018 based on the annual report data provided by the Iranian MS Society (IMSS) registry system. The age-standardized and crude prevalence were estimated using population data presented by the Statistical Centre of Iran.

Results: A total of 21,580 MS cases were registered and included in the analysis. Among the participant patients, $24.99 \%(5,393)$ and $75.01 \%(16,187)$ of cases were male and female, respectively. The mean age of MS onset was 28.8 years (S.D: 8.7). The agestandardized prevalence (ASP) of MS increased from 73.7 (95\%Cl: 72.1-75.2) per 100,000 people in 2006 to 137.6 (95\% Cl: 135.7-139.5) per 100,000 people in 2018. The ASP of MS in 2018 was estimated to be 67.9 (95\%Cl: 66.0-69.8) and 207.3 (95\%Cl: 204.0-210.7) per 100,000 people among males and females, respectively. The age-standardized female-to-male ratio of MS ranged from 3.7 (in 2010) to 2.06 (in 2017).

Conclusion: The findings of this study suggested that the prevalence of MS in Tehran province is relatively high, and the occurrence of the disease is more common in the age groups under 40 years as compared with older-aged groups. In line with reports provided for various regions of the world, the prevalence of MS was higher among women. Similarly, the findings of this study revealed that the female-to-male ratio was 2.14 in 2018.

\section{Background}

Multiple sclerosis (MS) is a chronic autoimmune neurological disease [1], which is recognized as the most prevalent inflammatory neuroimmunological disorder among young adults $[2,3]$.

The report of 2,221,188 MS cases in the world in 2016 as compared with 1990 represents an increase of over 10\%. The highest prevalence of MS was reported for North America, Western Europe, and Australia, while the lowest rate was related to Sub-Saharan Africa, Central Africa, and Oceania [4].

The incidence and prevalence of MS have been investigated in numerous studies, and various results have been reported in this regard [3-7]. The prevalence of MS is also different in various provinces of Iran [8]. The pertinent studies suggested that the occurrence of MS increased with the distance from the equator [9]. In this regard, the findings have revealed that while Africa and Asia have the lowest prevalence of MS, Northern Europe has reported the highest prevalence of MS [10]. Kurtzke [11] has divided different regions of the world into three categories of low (under 5 cases per 100,000 people), medium (5-25 cases per 100,000 people), and high (over 30 cases per 100,000 people) frequency regions in terms of MS incidence. Based on Kurtzke [11], Tehran is considered as a high frequency region for MS.

Previous studies have been conducted to estimate the incidence and prevalence of MS in Iran, and some of the mentioned studies have only investigated the familial MS [6, 12]. A recent study addressed the occurrence of MS in Tehran by examining the pertinent data obtained from 1991 to 2014 [13] and also another published study in Isfahan Province in 2014 was very brief. Therefore, considering the significant time trend in MS occurrence and the remarkable geographical variations in its incidence in Iran [8], further studies are required to be conducted to shed more light on the issue.

According to Hosseinzadeh et al. [8] and Kurtzke [11], Tehran is considered as one of the high-frequency provinces for MS. As the frequency of MS in Iran is high and varies over time, the present study aimed at investigating the longitudinal prevalence of MS in Tehran, Iran.

\section{Methods}

The present study was conducted addressing the population of Tehran, the capital of Iran. According to the 2016 population census conducted in Iran, the population of Tehran was 13,267,637, of which 6,673,672 (50.3\%) and 6,593,965 (49.7\%) were male and female, respectively. 
This population-based study was conducted in Tehran province of Iran based on the annual report data provided by the Iranian MS Society (IMSS) registry system from $1^{\text {st }}$ April 1999 to $31^{\text {st }}$ December 2018. The registration program as well as its validity and reliability has been described in the previous study [14]. Briefly, the Iranian MS Society, established in 1999, is the single registry center in Tehran and comprehensively registers baseline characteristics including patient identification, family history of MS, diagnosis, disease course, disability status, and medications. The required data set was determined according to 27 experts' opinions. Neurologists confirmed the disease diagnosis using the latest version of the McDonald criteria [15].

As IMSS provides extensive facilities for its members, all patients were encouraged by neurologists to refer to the IMSS to register and receive tracking code for receiving treatment and care services. The IMSS membership card must be activated by the patients every 5 year to keep their presence active. To design the present population-based cross-sectional study, it was tried to cover the most important epidemiological variables, which were related to MS recurrence at the individual level. The examined variables included sex, birth date (age), age at disease onset, and date of diagnosis.

A trained interviewer explained the objectives of the MS registry in IMSS to all patients. An informed written consent was obtained from all patients.

\section{Statistical Analyses}

Categorical and continuous data was presented as percentages and means (Standard Deviation (S.D.)). To calculate the prevalence of MS, direct standardization was used to adjust the effect of patients' age using the world standard population [16].

The MS prevalence estimate was calculated using the population data obtained from the Statistical Centre of Iran. Age-standardized prevalence (ASP) was calculated per 100,000 people by "dstdize" command in Stata software. The Poisson regression model was used to estimate the significance of change over time for total prevalence, sex-specific prevalence, and sex ratio of MS. All analyses were performed using Stata software, Version 14 (Stata Corp, College Station, TX).

To calculate the prevalence, the target population was determined using the 2006, 2011 and 2016 census of the Statistical Center of Iran; otherwise, the exponential formula was used to estimate the population as follows:

[Please see the supplementary files section to view the equation.]

where PT is the population to be estimated (population at time T), P0 stands for the population at time zero, $r$ is the growth rate that was considered as 1.44 [17] for 2007-2010 and 1.72 [18] for 2012-2015 and 2017-2018), and $t$ is the elapsed time from time zero in the mentioned years.

\section{Results}

\section{Age at disease onset and its trends}

In the present population-based MS registry, 21,580 cases of MS were registered and included in the analysis. 5,393 (24.99\%) and $16,187(75.01 \%)$ of the involved participants were male and female, respectively. The mean age of MS onset was 28.8 years (S.D: 8.7, ranged from 3-77 years). The mean age of males (29.5 years, S.D: 8.9) was significantly $(p<0.001)$ higher than that of females $(28.6$ years, S.D: 8.6). The mean age of MS onset in males and females in 2018 was 30.9 (S.D: 8.3) and 31.8 (S.D: 8.9) years, respectively. $13.4 \%$ of MS cases were familial MS patients. Demographic characteristics of MS cases are presented in Table 1.

\section{Age-standardized prevalence of MS}

In Table 2, the crude and ASP of MS were reported according to patients' sex. The ASP of MS increased from 73.7 (95\%Cl: 72.1-75.2) per 100,000 people in 2006 to 137.6 (95\% Cl: 135.7-139.5) per 100,000 people in 2018. The ASP of MS in 2018 was estimated to be 67.9 (95\% Cl: 66.0-69.8) and 207.3 (95\%Cl: 204.0-210.7) per 100,000 people among males and females, respectively. The results of Poisson regression model suggested that there was a significant change over time for the total prevalence $(p=0.001)$, prevalence among males $(\mathrm{p}=0.001)$, and prevalence among females $(\mathrm{P}=0.001)$.

The results showed that the prevalence of MS among females was significantly higher than that of males at all study years. Sexspecific prevalence data (count, population, prevalence) over the study period is show in Table 2. 


\section{Sex ratio trends}

The sex ratios over the 13-year study period are displayed in Figure 1. The sex ratio declined from 3.7 (in 2010) to 2.06 (in 2017) and had a decreasing trend. The results of Poisson regression model revealed that there was a significant change over time for sex ratio $(p=0.001)$.

\section{Discussion}

The current study examined the trend of MS prevalence in Tehran, the capital of Iran, from 2006 to 2018 . The results of this study suggested that the prevalence of MS in Tehran is increasing, and the unadjusted prevalence has increased from 79.3 cases per 100,000 people in 2006 to 151.7 cases per 100,000 people in 2018. Moreover, the age-standardized prevalence has increased from 73.7 cases per 100,000 people in 2006 to 137.6 cases per 100,000 people in 2018 .

Similar studies have been conducted in countries surrounding Iran, countries in the Middle East, and Arab countries; however, it is important to note that as Iranians are identified as Persian, the heredity and genetic structure of Iranian population differ from those of the mentioned countries. Other studies have also been conducted in various parts of Iran and have indicated that the pattern of MS disease in Tehran may be different from that of other parts of the country. The observed pattern can be attributed to a number of differences between Tehran and other cities including the higher level of air pollution in Tehran[19].

Therefore, according to the global divisions [20], Tehran should be considered as a region with a high MS prevalence (prevalence $\geq 30 / 100,000$ ). Moreover, Tehran has the highest MS prevalence in Asia and among the Middle Eastern countries [19]. In addition, the results revealed that the time trend of age-standardized MS female-to-male ratio in recent years has been declining to 2.14 in 2018.

A study conducted by Wallin MT et al. [3] in the United States in 2010 revealed that the prevalence of MS in the population aged over 18 years old was 309.2 per 100,000 people over 10 years. Moreover, the highest prevalence was reported for the 55-64 age group. As compared with the findings of the current study, in which most cases were observed in the age group below the age of 40 years, Wallin MT et al.'s study has a higher prevalence and a different age distribution. When coupled with prior estimates of the MS prevalence in Iran, it seems that there has been a relative increase in this regard over the last decades. In Eskandarieh et al.'s study [7], the MS prevalence in Tehran was 101.39 per 100,000 people in 2014, and the age-adjusted prevalence were 134 and 42.5 for females and males, respectively. In another review study, the MS prevalence in Iran was 85.8 per 100,000 people in 2013 [19].

According to Hosseinzadeh et al. [8], Tehran is considered as one of the high-frequency regions for MS. The high MS frequency in Tehran may be related to the rate of urbanization [21], the social and economic status [22, 23], and air pollution [24-26]. In addition, better access to health services can play an important role and in turn lead to better diagnosis and case registration [27].

Tehran has been recognized as one of the most polluted cities in the world [28]. Although some studies have not reported a significant association between MS and air pollution markers such as $\mathrm{PM}_{2.5}, \mathrm{NO}_{2}$, and $\mathrm{O}_{3}$ [29], several studies [24-26] have shown some evidences that air pollution can have a significant relationship with the incidence and recurrence of MS. Air pollution leads to deficiency of vitamin D, production of excessive free radical, expression of inflammatory factors, induction of chronic inflammation, dysfunction of mitochondrial, and increase of oxidative stress, all of which can be linked to MS incidence and recurrence [25, 26]. Therefore, as previous studies have shown [30], it can be hypothesized that a portion of the high prevalence of MS in Tehran may be attributable to the air pollution. To establish causality, it is recommended to compare different geographic regions with different pollution levels in terms of MS occurrence.

One finding presented in most of the pertinent studies is that women as compared with men are more susceptible to MS [31, 32]. In a study addressing a relatively large sample of Canadian MS patients, sex ratio was estimated to be 3.2, which was so similar to the findings of the current study[31]. Moreover, the sex ratio has been reported to be 3.06 in Eskandarieh et al.'s study [6]. A study conducted in Turkey [33] revealed that the prevalence of MS in Karabük and Akçakoca were 95.9 and 46.1 per 100,000 people, respectively [34]. In addition, the mentioned study indicated that the prevalence of MS in the Middle East and North Africa was 51.52 cases per 100,000 people [34]. The estimated prevalence in the current study revealed that MS is more prevalent in Tehran as compared with other cities in the Middle East countries. 
It should be noted that the trend of sex ratio in the present study was rather declining from 3.20 in 2006 to 2.14 in 2018 . Two main reasons can be provided to justify the increase of MS incidence among males in Iran. First, as a result of sanctions imposed on Iran over the last few years, the socioeconomic stressors have been increased among Iranian population, especially amongst men that are more responsible for providing the necessities of their family life. Second, men are more exposed to air pollution in Tehran while performing their roles in the society [30,35]. The obtained trend in the current study using the extracted data up to 2010 is in agreement with the world global trend, which indicates the increasing sex ratio in MS patients. However, the findings of the study examining the extracted data over recent years have demonstrated descending sex ratio changes, which are consistent with the findings of Norway, Tasmania, and Sweden researches. The mentioned studies have indicated the stable sex ratio changes and did not support the former ascending trend [31, 36, 37]. However, some studies have reported an increase in this trend [38, 39].

In terms of age groups, nearly $60 \%$ of cases in the current study were diagnosed with MS before the age of 30 years. Other similar studies have also shown a higher incidence rate of MS at an early age $[7,40]$. The disease onset in the early age leads to an increase in the number of years lived with disability (YLDs) and eventually to disability-adjusted life years (DALYs) [4, 41, 42].

The present study had some limitations and strengths. Considering that Tehran is a large province in terms of both the population and geographical area, and MS registration is elective, the MS registration may be incomplete and some cases may not be registered. Therefore, the obtained prevalence may be underestimated. In addition, it should be highlighted that as IMSS registration facilitates provide health care services for patients, the mentioned point can be regarded as a strong inducement that may facilitate the registration and retention processes and thus be considered as study strength.

\section{Conclusion}

The findings of this study suggested that the prevalence of MS in Tehran province is relatively high, and disease occurrence is more common in groups below 40 years of age as compared with the older age-range groups. The results suggested that the prevalence of MS was higher in women, and the trend of female-to-male sex ratio has been declining over the studied period.

\section{Abbreviations}

MS: Multiple Sclerosis

IMSS: Iranian MS Society

Cl: Confidence Interval

S.D: Standard Deviation

ASP: Age-Standardized Prevalence

\section{Declarations}

Ethics approval and consent to participate: The study was approved ethically by institutional review board of Tehran University of Medical Sciences, Tehran, Iran. An informed consent was obtained from each participant. In the study, the privacy of the participants was maintained.

Consent for publication: Not Applicable.

Availability of data and materials: The data sets used and analyzed during the study are available from the corresponding author on reasonable request.

Competing interests: The authors declare no competing interests.

Funding: This study was funded by Tehran University of Medical Sciences (TUMS), Tehran, Iran with the Grant Number 40376-188-0198. The founder had no role in the design of the study; in the collection, analysis, and interpretation of data; and in the writing process of the manuscript. 
Authors' contributions: MAS conceived and designed the study. Moreover, data collection was done by SE. Data analysis and interpretation was performed by AAH and SE. In addition, the manuscript was drafted by AAH and SE and was then critically revised by MAS. All authors read and approved the final version of the manuscript.

Acknowledgments: We would like to thank for research grant of Tehran University of medical sciences, all included patients and IMSS staffs.

\section{References}

1. García-Domínguez JM, Maurino J, Martínez-Ginés ML, Carmona O, Caminero AB, Medrano N, et al. Economic burden of multiple sclerosis in a population with low physical disability. BMC public health. 2019;19 1:609; doi: 10.1186/s12889-019-6907-x.

2. Stenager E. A global perspective on the burden of multiple sclerosis. The Lancet Neurology. 2019;18 3:227-8; doi: 10.1016/S14744422(18)30498-8.

3. Wallin MT, Culpepper WJ, Campbell JD, Nelson LM, Langer-Gould A, Marrie RA, et al. The prevalence of MS in the United States: A population-based estimate using health claims data. Neurology. 2019;92 10:e1029-e40; doi: 10.1212/wnl.0000000000007035.

4. Wallin MT, Culpepper WJ, Nichols E, Bhutta ZA, Gebrehiwot TT, Hay SI, et al. Global, regional, and national burden of multiple sclerosis 1990-2016: a systematic analysis for the Global Burden of Disease Study 2016. The Lancet Neurology. 2019;18 3:26985; doi: 10.1016/S1474-4422(18)30443-5.

5. Al-Sakran LH, Marrie RA, Blackburn DF, Knox KB, Evans CD. Establishing the Incidence and Prevalence of Multiple Sclerosis in Saskatchewan. The Canadian journal of neurological sciences Le journal canadien des sciences neurologiques. 2018;45 3:295303; doi: 10.1017/cjn.2017.301.

6. Eskandarieh S, Allahabadi NS, Sadeghi M, Sahraian MA. Increasing prevalence of familial recurrence of multiple sclerosis in Iran: a population based study of Tehran registry 1999-2015. BMC neurology. 2018;18 1:15; doi: 10.1186/s12883-018-1019-2.

7. Eskandarieh S, Heydarpour P, Elhami SR, Sahraian MA. Prevalence and Incidence of Multiple Sclerosis in Tehran, Iran. Iran J Public Health. 2017;46 5:699-704.

8. Hosseinzadeh A, Baneshi MR, Sedighi B, Kermanchi J, Haghdoost AA. Geographic variations of multiple sclerosis in Iran: A population based study. Multiple sclerosis and related disorders. 2019;28:244-9; doi: 10.1016/j.msard.2019.01.001.

9. Alonso A, Hernán MA. Temporal trends in the incidence of multiple sclerosis: a systematic review. Neurology. 2008;71 2:129-35.

10. Kurtzke J. Epidemiology of multiple sclerosis. Does this really point toward an etiology? Lectio Doctoralis. Neurological Sciences. 2000;21 6:383.

11. Kurtzke JF. A reassessment of the distribution of multiple sclerosis. Acta neurologica Scandinavica. 1975;51 2:137-57; doi: 10.1111/j.1600-0404.1975.tb01365.x.

12. Eskandarieh S, Molazadeh N, Moghadasi AN, Azimi AR, Sahraian MA. The prevalence, incidence and familial recurrence of multiple sclerosis in Tehran, Iran. Multiple sclerosis and related disorders. 2018;25:143; doi: 10.1016/j.msard.2018.07.023.

13. Eskandarieh S, Heydarpour P, Elhami S-R, Sahraian MA. Prevalence and Incidence of Multiple Sclerosis in Tehran, Iran. Iranian journal of public health. 2017;46 5:699-704.

14. Shahin S, Eskandarieh S, Moghadasi AN, Razazian N, Baghbanian SM, Ashtari F, et al. Multiple sclerosis national registry system in Iran: Validity and reliability of a minimum data set. Multiple sclerosis and related disorders. 2019;33:158-61; doi: 10.1016/j.msard.2019.06.009.

15. Polman CH, Reingold SC, Edan G, Filippi M, Hartung H-P, Kappos L, et al. Diagnostic criteria for multiple sclerosis: 2005 revisions to the "McDonald Criteria". Annals of Neurology. 2005;58 6:840-6; doi: 10.1002/ana.20703.

16. National Institutes of Health. Standard Populations - 19 Age Groups. https://seer.cancer.gov/stdpopulations/stdpop.19ages.html (2019). Accessed July 2019.

17. Statistical Center of Iran. Selected Findings of the 2011 National Population and Housing Census. https://www.amar.org.ir/Portals/1//ran/Atlas_Census_2011.pdf (2014). Accessed September 2019.

18. Statistical Center of Iran. Results of the 2016 National Population and Housing Census. https://www.amar.org.ir/Portals/0/census/1395/results/ch_nsonvm_95.pdf (2018). Accessed September 2019.

19. Eskandarieh S, Heydarpour P, Minagar A, Pourmand S, Sahraian MA. Multiple Sclerosis Epidemiology in East Asia, South East Asia and South Asia: A Systematic Review. Neuroepidemiology. 2016;46 3:209-21; doi: 10.1159/000444019.

Page 6/10 
20. Kurtzke JF. Multiple sclerosis in time and space--geographic clues to cause. Journal of neurovirology. 2000;6 Suppl 2:S134-40.

21. Dehghani R, Yunesian M, Sahraian MA, Gilasi HR, Kazemi Moghaddam V. The Evaluation of Multiple Sclerosis Dispersal in Iran and Its Association with Urbanization, Life Style and Industry. Iran J Public Health. 2015;44 6:830-8.

22. Conway DS. What is the impact of socioeconomic status on multiple sclerosis? About multiple sclerosis. Neurology. $2019 ; 92$ 13:e1536-e9.

23. Calocer F, Dejardin O, Droulon K, Launoy G, Defer G. Socio-economic status influences access to second-line disease modifying treatment in Relapsing Remitting Multiple Sclerosis patients. PLOS ONE. 2018;13 2:e0191646; doi: 10.1371/journal.pone.0191646.

24. Mehrpour M, Shams-Hosseini NS, Rezaali S, Sahraiian MA, Taki S. Effect of Air Pollutant Markers on Multiple Sclerosis Relapses. Iranian journal of public health. 2013;42 10:1167-73.

25. Esmaeil Mousavi S, Heydarpour P, Reis J, Amiri M, Sahraian MA. Multiple sclerosis and air pollution exposure: Mechanisms toward brain autoimmunity. Medical Hypotheses. 2017;100:23-30; doi: https://doi.org/10.1016/j.mehy.2017.01.003.

26. Ashtari F, Esmaeil N, Mansourian M, Poursafa P, Mirmosayyeb O, Barzegar M, et al. An 8-year study of people with multiple sclerosis in Isfahan, Iran: Association between environmental air pollutants and severity of disease. Journal of Neuroimmunology. 2018;319:106-11; doi: 10.1016/j.jneuroim.2018.02.019.

27. Mohebi F, Eskandarieh S, Mansournia MA, Mohajer B, Sahraian MA. Multiple Sclerosis in Tehran: Rising Prevalence alongside Stabilizing Incidence - True Increase or Enhanced Diagnosis? Archives of Iranian medicine. 2019;22 8:429-34.

28. Jamaati H, Attarchi M, Hassani S, Farid E, Seyedmehdi SM, Pormehr PS. Investigating air quality status and air pollutant trends over the Metropolitan Area of Tehran, Iran over the past decade between 2005 and 2014. Environ Health Toxicol. 2018;33 2:e2018010-e; doi: 10.5620/eht.e2018010.

29. Bai L, Burnett RT, Kwong JC, Hystad P, van Donkelaar A, Brook JR, et al. Long-term exposure to air pollution and the incidence of multiple sclerosis: A population-based cohort study. Environmental research. 2018;166:437-43; doi: 10.1016/j.envres.2018.06.003.

30. Heydarpour P, Amini H, Khoshkish S, Seidkhani H, Sahraian MA, Yunesian M. Potential impact of air pollution on multiple sclerosis in Tehran, Iran. Neuroepidemiology. 2014;43 3-4:233-8; doi: 10.1159/000368553.

31. Orton S-M, Herrera BM, Yee IM, Valdar W, Ramagopalan SV, Sadovnick AD, et al. Sex ratio of multiple sclerosis in Canada: a longitudinal study. The Lancet Neurology. 2006;5 11:932-6; doi: https://doi.org/10.1016/S1474-4422(06)70581-6.

32. Koch-Henriksen N, Sorensen PS. The changing demographic pattern of multiple sclerosis epidemiology. The Lancet Neurology. 2010;9 5:520-32; doi: 10.1016/s1474-4422(10)70064-8.

33. Börü ÜT, Bilgiç AB, Köseoğlu Toksoy C, Yılmaz AY, Tasdemir M, Sensöz NP, et al. Prevalence of Multiple Sclerosis in a Turkish City Bordering an Iron and Steel Factory. J Clin Neurol. 2018;14 2:234-41; doi: 10.3988/jcn.2018.14.2.234.

34. Heydarpour P, Khoshkish S, Abtahi S, Moradi-Lakeh M, Sahraian MA. Multiple Sclerosis Epidemiology in Middle East and North Africa: A Systematic Review and Meta-Analysis. Neuroepidemiology. 2015;44 4:232-44; doi: 10.1159/000431042.

35. Aloosh M, Salavati A, Aloosh A. Economic sanctions threaten population health: the case of Iran. Public Health. 2019;169:10-3; doi: https://doi.org/10.1016/j.puhe.2019.01.006.

36. Bostrom I, Stawiarz L, Landtblom AM. Sex ratio of multiple sclerosis in the National Swedish MS Register (SMSreg). Multiple sclerosis (Houndmills, Basingstoke, England). 2013;19 1:46-52; doi: 10.1177/1352458512446169.

37. Simpson S, Jr., Pittas F, van der Mei I, Blizzard L, Ponsonby AL, Taylor B. Trends in the epidemiology of multiple sclerosis in Greater Hobart, Tasmania: 1951 to 2009. Journal of neurology, neurosurgery, and psychiatry. 2011;82 2:180-7; doi: 10.1136/jnnp.2010.215186.

38. Trojano M, Lucchese G, Graziano G, Taylor BV, Simpson S, Jr., Lepore V, et al. Geographical variations in sex ratio trends over time in multiple sclerosis. PloS one. 2012;7 10:e48078-e; doi: 10.1371/journal.pone.0048078.

39. Holmberg M, Murtonen A, Elovaara I, Sumelahti M-L. Increased Female MS Incidence and Differences in Gender-Specific Risk in Medium- and High-Risk Regions in Finland from 1981-2010. Multiple Sclerosis International. 2013;2013:6; doi: $10.1155 / 2013 / 182516$.

40. Greer JM, McCombe PA. Role of gender in multiple sclerosis: clinical effects and potential molecular mechanisms. J Neuroimmunol. 2011;234 1-2:7-18; doi: 10.1016/j.jneuroim.2011.03.003.

41. Chung S-E, Cheong H-K, Park J-H, Kim HJ. Burden of disease of multiple sclerosis in Korea. Epidemiol Health. 2012;34:e2012008-e; doi: 10.4178/epih/e2012008.

Page $7 / 10$ 
42. Mansouri S, Zayeri F. Global and Regional Trends of Multiple Sclerosis Disability-Adjusted Life Years Rates: A 25-Year Assessment. Neuroepidemiology. 2019;52 1-2:17-24; doi: 10.1159/000492819.

\section{Tables}

Table 1. Demographic characteristics of MS cases at the onset of the disease in Tehran, Iran

\begin{tabular}{|c|c|c|}
\hline \multicolumn{2}{|c|}{ Variables } & $\mathrm{N}(\%)$ \\
\hline Sex & Male & $5393(24.99)$ \\
& Female & $16187(75.01)$ \\
\hline Age & $\leq 18$ & $2023(9.7)$ \\
& $19-24$ & $5098(24.7)$ \\
& $25-29$ & $4807(23.3)$ \\
& $30-34$ & $3704(18.0)$ \\
& $35-39$ & $2395(11.6)$ \\
& $40-44$ & $1518(7.4)$ \\
& $\geq 45$ & $1091(5.3)$ \\
\hline Familial MS & Yes & $2815(13.4)$ \\
& No & $18145(86.6)$ \\
\hline
\end{tabular}

Table 2: The crude and age standardized prevalence of MS in Tehran, Iran during 2006-2018 


\begin{tabular}{|c|c|c|c|c|c|c|c|c|c|c|c|c|}
\hline \multirow[t]{2}{*}{ Year } & \multicolumn{4}{|l|}{ Female } & \multicolumn{4}{|l|}{ Male } & \multicolumn{4}{|l|}{ Total } \\
\hline & Population & Count & Prevalence & $\begin{array}{l}\text { ASPI } \\
(95 \% \mathrm{CI})\end{array}$ & Population & Count & Prevalence & $\begin{array}{l}\text { ASPI } \\
(95 \% \mathrm{CI})\end{array}$ & Population & Count & Prevalence & $\begin{array}{l}\text { ASPI } \\
(95 \% \mathrm{CI})\end{array}$ \\
\hline 2006 & 5513872 & 6848 & 124.2 & $\begin{array}{l}115.4 \\
(112.6- \\
118.2) \\
\end{array}$ & 5831418 & 2146 & 36.8 & $\begin{array}{l}33.9 \\
(32.4- \\
25.3) \\
\end{array}$ & 11345290 & 8994 & 79.3 & $\begin{array}{l}73.7 \\
(72.1- \\
75.2) \\
\end{array}$ \\
\hline 2007 & 5593267 & 7633 & 136.5 & $\begin{array}{l}126.7 \\
(123.8- \\
129.6)\end{array}$ & 5915395 & 2397 & 40.5 & $\begin{array}{l}37.2 \\
(35.7- \\
38.7)\end{array}$ & 11508662 & 10030 & 87.2 & $\begin{array}{l}80.9 \\
(79.3- \\
82.5)\end{array}$ \\
\hline 2008 & 5673810 & 8447 & 148.9 & $\begin{array}{l}137.9 \\
(134.9- \\
141.0) \\
\end{array}$ & 6000577 & 2665 & 44.4 & $\begin{array}{l}40.9 \\
(39.3- \\
42.5) \\
\end{array}$ & 11674387 & 11112 & 95.2 & $\begin{array}{l}88.3 \\
(86.6- \\
90.0) \\
\end{array}$ \\
\hline 2009 & 5755513 & 9232 & 160.4 & $\begin{array}{l}148.3 \\
(145.2- \\
151.4) \\
\end{array}$ & 6086985 & 2930 & 48.1 & $\begin{array}{l}44.3 \\
(42.7- \\
45.9) \\
\end{array}$ & 11842498 & 12162 & 102.7 & $\begin{array}{l}95.1 \\
(93.4- \\
96.8) \\
\end{array}$ \\
\hline 2010 & 5838393 & 10160 & 174.0 & $\begin{array}{l}160.6 \\
(157.4- \\
163.8) \\
\end{array}$ & 6174637 & 3198 & 51.8 & $\begin{array}{l}47.7 \\
(46.0- \\
49.3) \\
\end{array}$ & 12013030 & 13358 & 111.2 & $\begin{array}{l}102.8 \\
(101.0- \\
104.6) \\
\end{array}$ \\
\hline 2011 & 6045398 & 11187 & 185.1 & $\begin{array}{l}170.2 \\
(167.0- \\
173.4) \\
\end{array}$ & 6137993 & 3513 & 57.2 & $\begin{array}{l}52.4 \\
(50.6- \\
54.2) \\
\end{array}$ & 12183391 & 14700 & 120.7 & $\begin{array}{l}111.2 \\
(109.3- \\
113.0) \\
\end{array}$ \\
\hline 2012 & 6149379 & 12028 & 195.6 & $\begin{array}{l}179.4 \\
(176.1- \\
182.7) \\
\end{array}$ & 6243566 & 3780 & 60.6 & $\begin{array}{l}55.3 \\
(53.5- \\
57.1) \\
\end{array}$ & 12392945 & 15808 & 127.6 & $\begin{array}{l}117.2 \\
(115.4- \\
119.1) \\
\end{array}$ \\
\hline 2013 & 6255149 & 12867 & 205.7 & $\begin{array}{l}188.2 \\
(184.9- \\
191.5) \\
\end{array}$ & 6350955 & 4083 & 64.3 & $\begin{array}{l}58.7 \\
(56.8- \\
60.5) \\
\end{array}$ & 12606104 & 16950 & 134.5 & $\begin{array}{l}123.3 \\
(121.4- \\
125.2) \\
\end{array}$ \\
\hline 2014 & 6362737 & 13583 & 213.5 & $\begin{array}{l}194.9 \\
(191.5- \\
198.2) \\
\end{array}$ & 6460192 & 4357 & 67.5 & $\begin{array}{l}61.4 \\
(59.6- \\
63.3) \\
\end{array}$ & 12822929 & 17940 & 139.9 & $\begin{array}{l}128.0 \\
(126.1- \\
129.9) \\
\end{array}$ \\
\hline 2015 & 6472176 & 14211 & 219.6 & $\begin{array}{l}200.0 \\
(196.7- \\
203.4)\end{array}$ & 6571307 & 4591 & 69.9 & $\begin{array}{l}63.6 \\
(61.7- \\
65.4)\end{array}$ & 13043483 & 18802 & 144.2 & $\begin{array}{l}131.6 \\
(129.7- \\
133.6)\end{array}$ \\
\hline 2016 & 6593965 & 14875 & 225.6 & $\begin{array}{l}205.0 \\
(201.7- \\
208.4) \\
\end{array}$ & 6673672 & 4828 & 72.3 & $\begin{array}{l}65.7 \\
(63.8- \\
67.6) \\
\end{array}$ & 13267637 & 19703 & 148.5 & $\begin{array}{l}135.3 \\
(133.4- \\
137.3) \\
\end{array}$ \\
\hline 2017 & 6693000 & 15304 & 228.7 & $\begin{array}{l}207.6 \\
(204.2- \\
210.9) \\
\end{array}$ & 6768000 & 5037 & 74.4 & $\begin{array}{l}67.5 \\
(65.6- \\
69.4) \\
\end{array}$ & 13461000 & 20341 & 151.1 & $\begin{array}{l}137.5 \\
(135.6- \\
139.5) \\
\end{array}$ \\
\hline 2018 & 6784000 & 15505 & 228.6 & $\begin{array}{l}207.3 \\
(204.0- \\
210.7) \\
\end{array}$ & 6853000 & 5131 & 74.9 & $\begin{array}{l}67.9 \\
(66.0- \\
69.8) \\
\end{array}$ & 13636000 & 20636 & 151.3 & $\begin{array}{l}137.6 \\
(135.7- \\
139.5)\end{array}$ \\
\hline
\end{tabular}

${ }^{*}$ Crude Prevalence (Per 100,000) ${ }^{\square}$ Age Standardized Prevalence (Per 100,000)

\section{Figures}




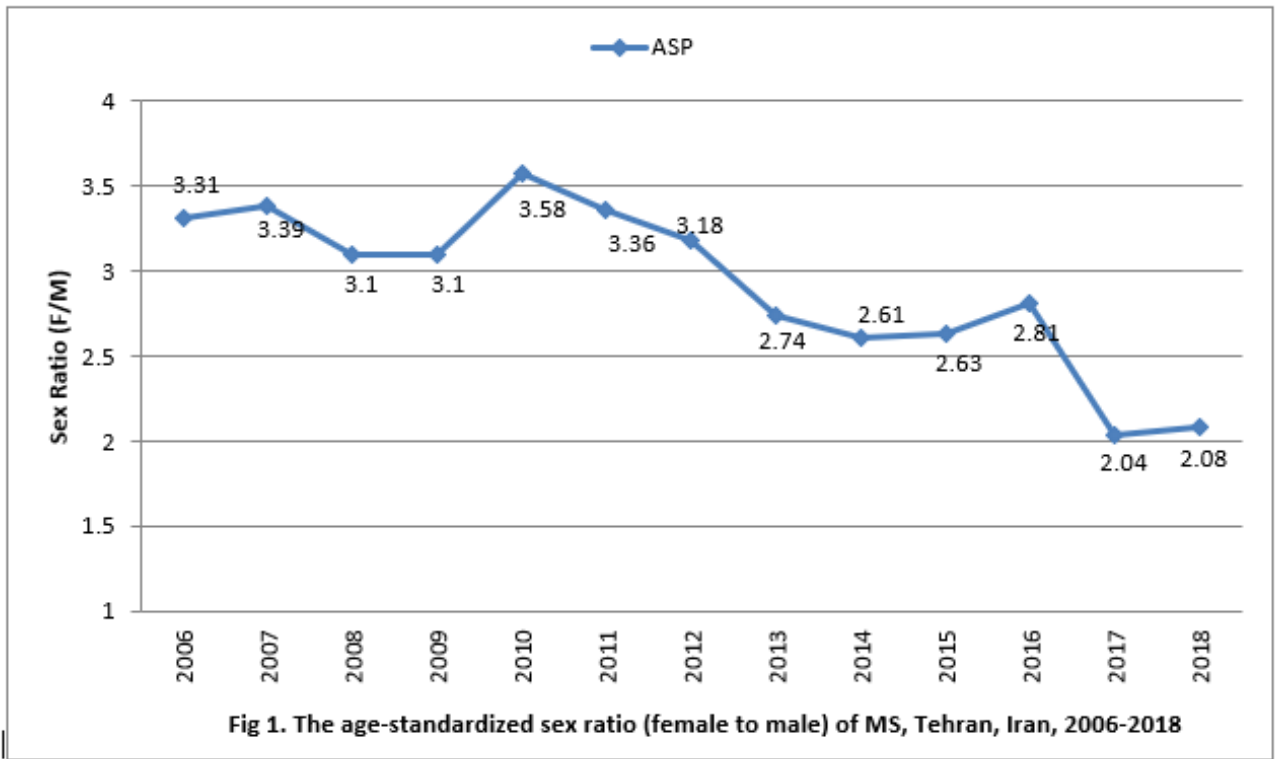

\section{Figure 1}

The sex ratios over the 13-year study period.

\section{Supplementary Files}

This is a list of supplementary files associated with this preprint. Click to download.

- Equation.docx 